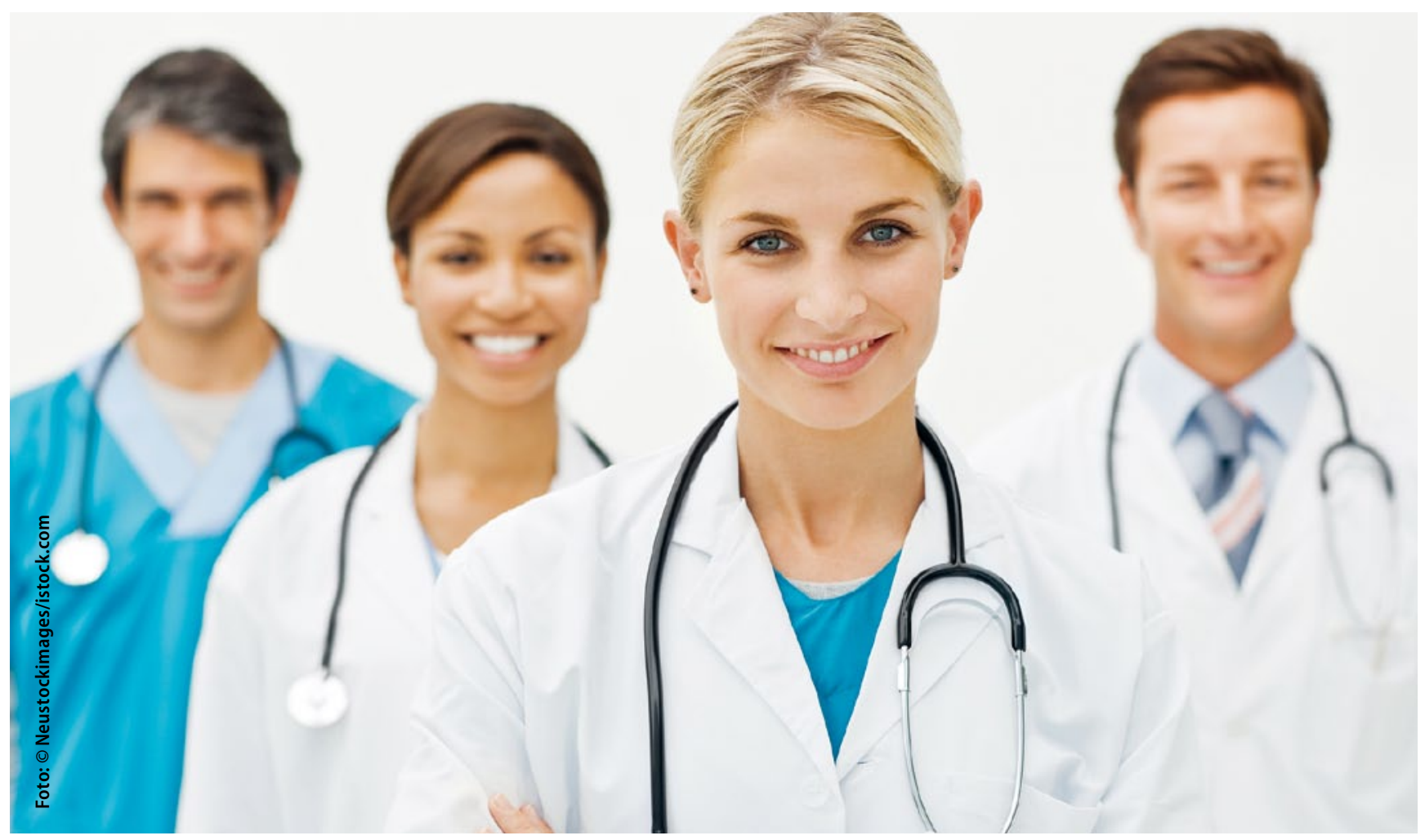

\title{
Learnings from "healthymagination" - How GE Provides Better Care to More People at Lower Cost
}

\begin{abstract}
Healthcare is at a crossroads. There is enormous pressure on governments to reduce costs; hospitals and clinicians are looking to improve quality; and an increasing population is striving to get access to medical care. Current healthcare models are in many ways not fit to meet these challenges. The "healthymagination" strategy of GE is designed to meet the growing demands of the market. This initiative that emphasizes customer-driven innovation, stakeholder orientation and multiple communication channels significantly helps reduce costs, improve quality and increase patient access.
\end{abstract}

DENNIS HERHAUSEN | MARKUS TRUMANN | MARCUS SCHÖGEL

$\mathrm{H}$ ealthcare providers are facing a myriad of challenges, including the rise of unprecedented disease, aging populations and escalating costs. Rates of chronic disease are exploding all over the world. For example, 1 billion people worldwide are overweight, 73 million Americans have high blood pressure, accounting for 1 in 6 deaths, and by 2020, heart disease and stroke will have become the leading causes of both death and disability worldwide. It is estimated that by 2039, 50\% of the global population will be over 65 . In addition to these grievances, many governments have to reduce costs or serve more people with the same budget. Annual global health care spending already amounts to US\$ 4 trillion. In 2008, U.S. health care spending equaled $16 \%$ of GDP, Switzerland's was at $10.7 \%$, and Germany's at $10.5 \%$, with an upward tendency (OECD 2010).

In summary, the global healthcare industry is in need of help. Governments are looking for possibilities to reduce costs, hospitals and clinicians try to develop better treatment processes, and patients around the world need treatments that are economically viable. Current healthcare models are in many ways unsustainable and not fit to meet these challenges due to their focus on high-end innovation, a strong physician and hospital orientation and the use of traditional communication channels. These insights set the stage for a new approach to global healthcare introduced at GE in 2009 and called "healthymagination". 


\section{What is "healthymagination"?}

In 2005, GE identified future trends that will become more and more important during the course of the 21st century, two of them being a shortage of resources and an increasing demand for health services. As a first step, GE started its sustainable differentiation strategy "ecomagination" in 2006 (Trumann/Herhausen 2008). "healthymagination" extends this approach and translates the assessment of a global trend into a companywide strategy.

In 2009, faced with these healthcare challenges, GE made a sixyear, US\$ 6 billion commitment to healthcare innovation that will provide better care for more people at lower cost. As a global leader in healthcare technology, capital finance and performance optimization, GE was uniquely positioned to tackle these challenges. Although healthymagination is grounded in GE Health- care, the initiative also incorporates GE Capital, GE Global Research, GE Water and NBC Universal. Furthermore, GE has strengthened its cooperation with external partners to focus on critical needs and is engaged in constant communication with opinion leaders and policymakers so as to be able to learn from their experience. Until 2015, GE will invest US\$ 3 billion in 100 innovations that will lower costs, improve access, and improve quality; US $\$ 2$ billion in IT and access in rural and underserved areas; and US $\$ 1$ billion in partnerships, media content, and services. These commitments will help meet the challenges that patients, healthcare providers and society at large are faced with. A special focus of healthymagination is on accelerating health care information technology, providing high-tech products at more affordable prices, giving underserved consumers better

\section{Fig. 1 Commitments and Shifting Focus of GE Healthcare}

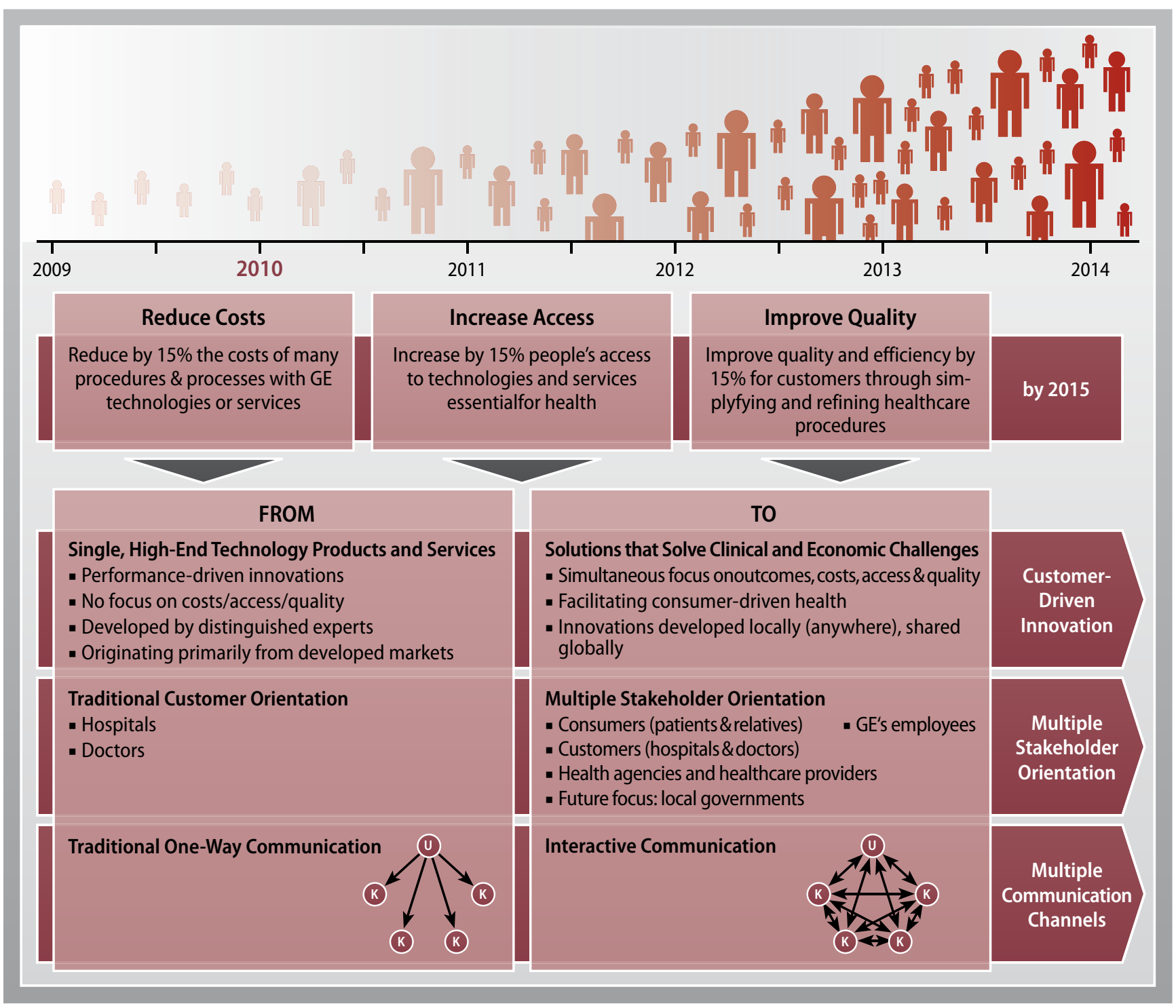


access to medical care and supporting consumer-driven healthcare solutions.

In line with recent suggestions by different marketing authorities (Kotler et al. 2010; Marketing Science Institute 2010; Rust et al. 2010), GE's business transformation, as represented by healthymagination, focused on three main areas: innovation, stakeholder orientation and communication channels (figure 1). First, there is an urgent need for innovation in terms of the delivery of healthcare. In the past, healthcare innovations focused on outcomes and were mainly created by distinguished healthcare institutions primarily in developed countries. In today's interconnected world, healthcare innovations can be developed anywhere and shared globally almost instantaneously while simultaneously focusing on outcomes, cost, access, and quality. Second, healthcare providers need to broaden their stakeholder orientation. The traditional orientation towards hospitals and physicians is insufficient, given the many different stakeholders within the healthcare arena. Third, a real dialogue regarding healthcare issues is required to create awareness for people's health habits. Traditional one-way communication channels appear to be inappro- priate to change consumers' minds. In the following, the authors describe the shifting focus of GE and the performance implications of healthymagination.

\section{Customer-Driven Innovation}

Due to healthymagination, GE adjusted its innovation focus from single, high-end technology products towards solutions for customers that solve clinical and economic challenges. While in the past healthcare innovation at GE was characterized by cost-intensive, performance-driven solutions, current activities aim at introducing more affordable, simpler solutions. In line with the ideas of Chesbrough (2003) and Ulwick (2005), GE integrates customer input to determine opportunities to reduce costs, improve quality and increase access. However, GE not only cooperates with its traditional customers, hospitals and physicians, but also with patients and their relatives, governmental organizations and other market players. The resulting customer-driven innovations focus on four fields: information acceleration, efficient technology, local access and engaging patients.

\section{Fig. 2 Customer-Driven "Threefold“ Innovations}

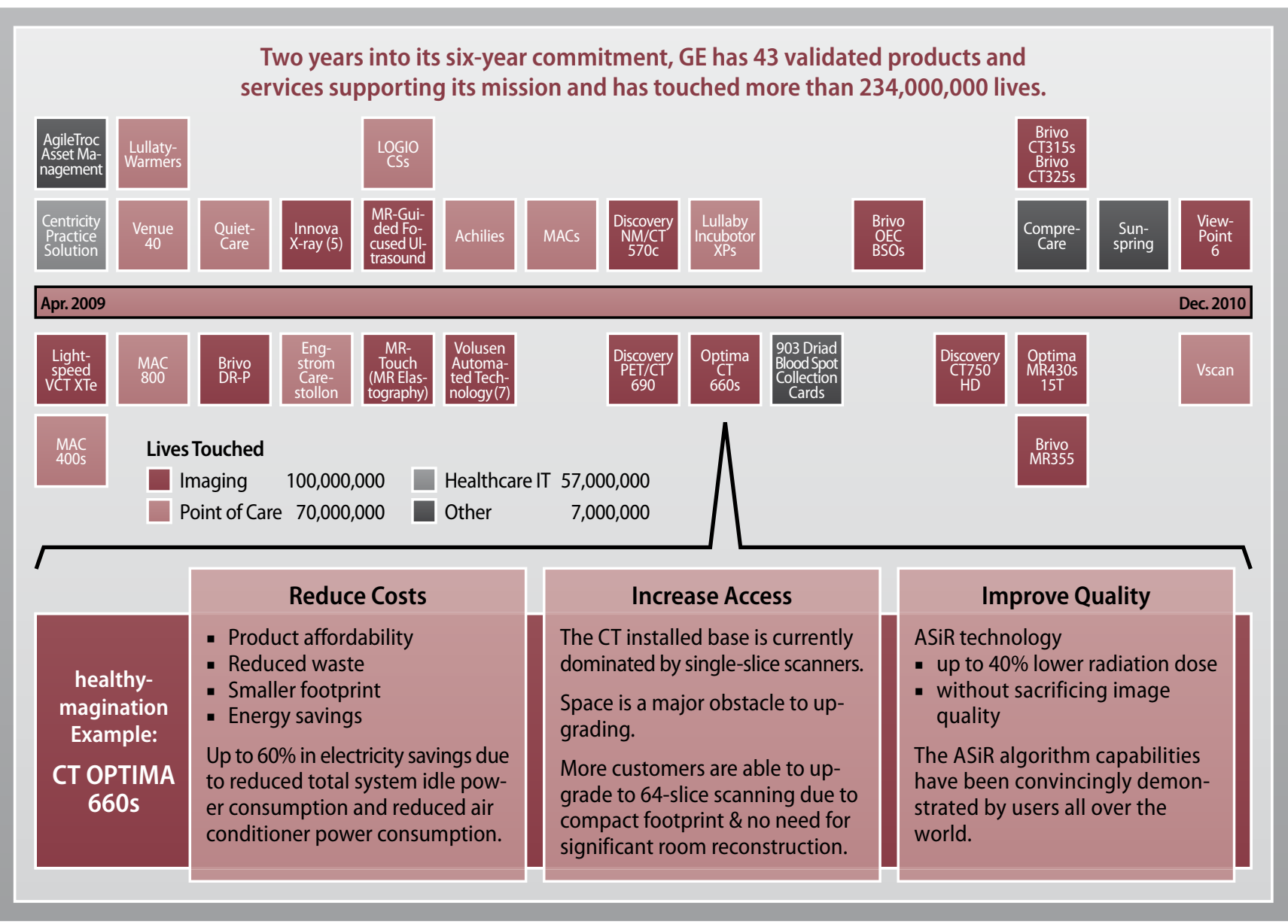


- Information Acceleration: GE advances the adoption of healthcare information technology to provide hospitals and doctors with decision support and productivity tools. For example, a joint venture between GE, Omnyx and the University of Pittsburgh Medical Center is developing a digital platform for lab pathology to improve diagnostics and lower costs.

- Efficient Technology: GE develops technologies that help customers utilize their existing infrastructure more efficiently. For example, GE's AgileTrac Asset Manager allows hospitals to use equipment more efficiently so fewer pieces of equipment need to be purchased. The RFID tracking system also reduces the demand for rental equipment, minimizes equipment theft and loss, helps ensure proper equipment sanitation and maintenance and provides critical data needed for accurate capital budgeting.

\section{"A real dialogue regarding healthcare issues is required to create awareness for people's health habits. "}

- Local Access: GE creates services and devices that are targeted to meet the specific needs of specific regions, e.g., rural and underserved regions that need the essentials of healthcare, energy, and financing. In such regions, GE is cooperating with the Nobel-prize winning Grameen Bank of Bangladesh to develop a sustainable rural health model that will reduce maternal and infant mortality by more than 20 percent.

- Engaging Patients: GE supports consumer-driven health programs and innovative hospital programs that boost and motivate consumer health awareness and activity. For example, GE and Intel are working together and combining their complementary skills to accelerate the innovation and commercialization of next-generation home health technologies, including new areas such as fall prevention, medication compliance, and monitoring of sleep apnea, cardiovascular disease, diabetes and personal wellness.

To get fully certified as a healthymagination initiative, innovations have to both reduce costs and increase access and quality of care by at least $15 \%$. These achievements are externally controlled. Oxford Analytica has developed a rigorous evidence-based method for reviewing GE's portfolio of innovations and assessing on a systematic basis whether they meet the healthymagination criteria, i.e., drive improvements in cost, quality and access to health services. Cost savings may result from a variety of factors, such as decreased treatment time, fewer unnecessary interventions, reduced length of hospital stay or lower administration costs.

Increased access to health services and technologies can take various forms, such as providing medical equipment to developing and rural markets where the travel distance to healthcare cent- ers can be a significant obstacle or offering medical technologies which can be used in primary care settings, thus reducing the need for hospital referrals. Designing products that address the needs of underserved markets is just the first step towards improving access. As a next step, the product has to be introduced successfully into those markets and has to show that it actually contributes to improving healthcare in a sustainable manner.

Improved quality of care can take many forms, ranging from reduced morbidity and mortality rates to fewer unnecessary hospitalizations, a reduced number of medical errors, or enhanced patient comfort and quality of life. Improvements in the quality of care can result from the use of technologies that are established and proven, or from new technologies showing potential or actual improvement over existing products. Figure 2 shows an example of a successful innovation, Optima CT660, which has been fully healthymagination-validated because it reduces costs by $15 \%$ and increases access and quality of care by $15 \%$.

\section{Multiple Stakeholder Orientation}

But healthymagination means more than just new products. GE Healthcare was traditionally a B2B company focusing on hospitals and physicians as their customers. However, this was a myopic customer orientation in two different ways. First, GE did not sufficiently consider consumers - the customers of their customers: the patients who are treated with GE's devices and their relatives. Thus, GE missed the opportunity to benefit from the pull of the market. Second, GE is now also putting more emphasis on additional healthcare stakeholders, e.g., governmental organizations, independent opinion leaders, competitors and cooperation partners, and their own employees. In doing so, GE is becoming a company with a multiple stakeholder orientation which helps to balance the interests of all relevant market players and the unfolding market needs (Ferrell et al. 2010). Different activities of GE address consumers (patients and relatives), customers (hospitals and physicians), health agencies and healthcare providers, and their own employees.

To address patients and their relatives, GE supplies these consumers with the tools they need to make healthier choices every day. For example, GE partnered with the Cleveland Clinic and Ochsner Health System and conducted a national consumer study in the United States to gain a better understanding of people's health habits and to ultimately improve the way patients communicate with their doctors. The study revealed a large gap between individuals' and doctors' perceptions of healthy living. While most

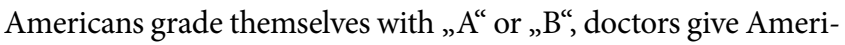
cans low grades on personal health (GE et al. 2010). These results became the cornerstone of a global campaign - The Year of Better Health for More People - designed to inspire people to lead healthier and more productive lives.

Doctors, nurses and hospital administrators still are key contact persons for GE. Addressing their needs, GE Performance Solutions has saved approximately US\$ 91 million in unnecessary costs by 
helping hospitals across the United States to simplify processes, open up additional capacity to treat people using current infrastructure and ensuring the right tools are on hand to address patient needs. 98 percent of these costs were recurring year after year. This means that GE has worked with hospital partners to save almost half a billion in unnecessary costs over the next five years. Due to lower costs and a simpler system, doctors and nurses can now offer better care to more people.

In addition, GE is striving for partnerships with key health agencies and healthcare providers to offer solutions to some of the world's most critical health needs. For example, GE's partnership with the UK in its National Stroke Strategy aims to reduce the death rate from stroke by raising awareness of early warning signs and implementing a clinically validated three-minute MRI stroke protocol. This helps ensure patients are scanned as soon as possible to avoid losing crucial time.

Furthermore, GE realized that healthcare starts at home. Although GE has been providing employees with health coverage since the 1930s, it just recently started to lead the charge in improving workplace health through Health Ahead, an innovative employee engagement program. Employees and their family members are encouraged to improve their health. They receive financial incentives to induce them to live a healthier life, e.g., by engaging in regular exercise or developing healthy eating habits. GE sites across the globe will be certified based on health- and wellness-related measures, including subsidized healthy foods in cafeterias and lower-cost fitness center options. This program could not only lead to $\$ 75$ million of savings, it will also significantly improve the health of GE's employees and transform them into healthcare mavens.
Just like innovations, the stakeholder orientation of GE also helps reduce costs and increase access and quality (figure 3). Addressing multiple stakeholders leads to more insights regarding the needs of different healthcare actors, unlocks hidden synergies and contributes to the objectives of healthymagination.

\section{Multiple Communication Channels}

Besides developing healthymagination-certified innovations and introducing a multiple stakeholder orientation, GE also improved its connection with healthcare consumers. More specifically, GE now takes the healthymagination message directly to consumers to help them change their approach to health. Due to the general changes in consumers' communication behavior (Li/Bernoff 2008) and the alarming results of the national consumer study in the United States, GE also revised its communication strategy. While in the past the focus was on traditional communication channels, mainly communicating through brochures and by educating healthcare providers, the focus has now moved towards interactive communication using multiple channels. A real dialogue among patients and providers has been established, including traditional media, healthcare ambassadors, digital media, social networks, and mobile applications.

GE used a large global event, the 2010 Winter Olympics in Vancouver, to launch the most comprehensive health communications program in GE history. The advertising campaign in traditional media allowed GE to reach millions of consumers in the United States and Canada simultaneously. A heavy-rotation television campaign was launched on NBC during the Opening Ceremo-

\section{Fig. 3 GE's Multiple Stakeholder Orientation}

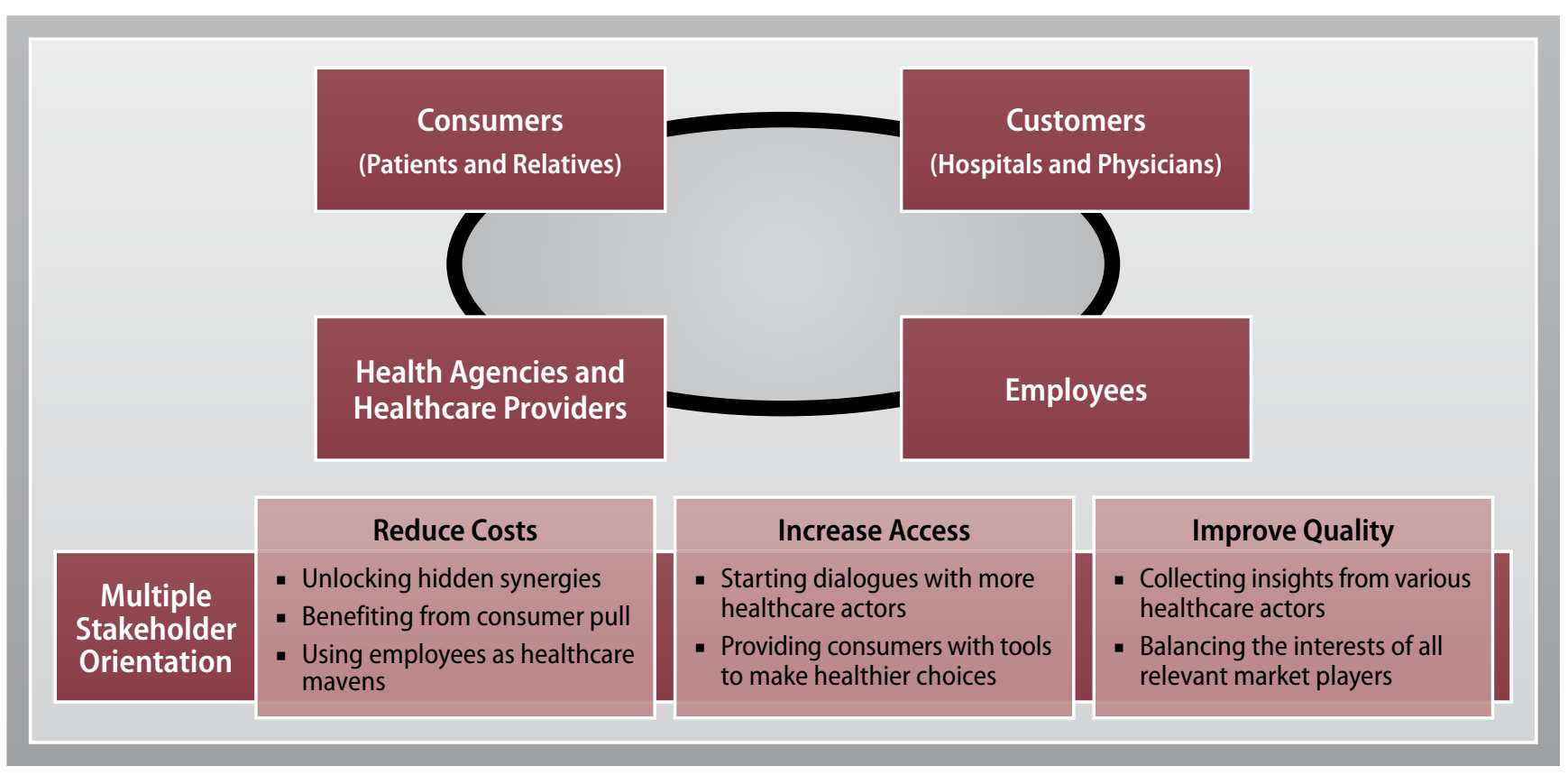


nies, and print and digital ads appeared in top-tier publications like the Wall Street Journal, USA Today, Washington Post and New York Times. GE also utilized outdoor ad space for added exposure in major markets in both Canada and the United States. To start a conversation with consumers, the company enlisted Olympic athletes like Michelle Kwan and Scott Hamilton as healthcare ambassadors to speak directly to consumers about health habits. Furthermore, GE re-launched healthymagination. com, a consumer-friendly site which informs about the program and related projects, offers mobile applications for consumers and features stories and blog posts around health topics. Online exposure was further increased by presence on Facebook, Twitter, HowCast, GOOD magazine and YouTube. Together with HowCast, GE developed a viral video campaign, the healthymagination "Physical Challenge", featuring 6 YouTube stars that told GE's story and created videos solely for this campaign. These videos gained over 10 million views, with a high user engagement demonstrated by 110,000 comments and 250,000 ratings with an average of 4.7 out of 5 stars (HowCast 2011). In partnership with MedHelp, the world's largest health social network, GE created a number of mobile applications to help consumers access helpful health information. Some of the apps featured are "Morsel", an educational tool to help people make healthier choices, „Pic Healthy", an interactive photo food diary, or "Sleep on it", a tracker of sleep patterns. These apps, which have been downloaded more than half a million times, are now in the hands of people around the world, providing solutions to common health issues, like helping women have healthier pregnancies and encouraging longterm weight loss.

The empowerment of consumers through multiple forms of communication creates easy access to valuable information and contributes to the cost saving, access and quality commitments of healthymagination (figure 4).

\section{Key Results of healthymagination}

Launched two years ago, the healthymagination initiative of GE with its clear commitment to customer-driven innovation, multiple stakeholder orientation and utilization of a wide range of communication channels has proven a huge success. Not only was GE able to strengthen its competitive positioning, healthymagination also contributed to the wealth of all targeted stakeholders. Successful stakeholders, in turn, not only create demand for GE's products but also provide critical public assets and a supportive environment (Porter/Kramer 2011).

Physicians and hospitals benefit from 43 products and services that have been validated and have touched more than $234,000,000$ lives. People around the world are gaining access to better and

\section{Fig. 4 Multiple Communication Channels at GE}

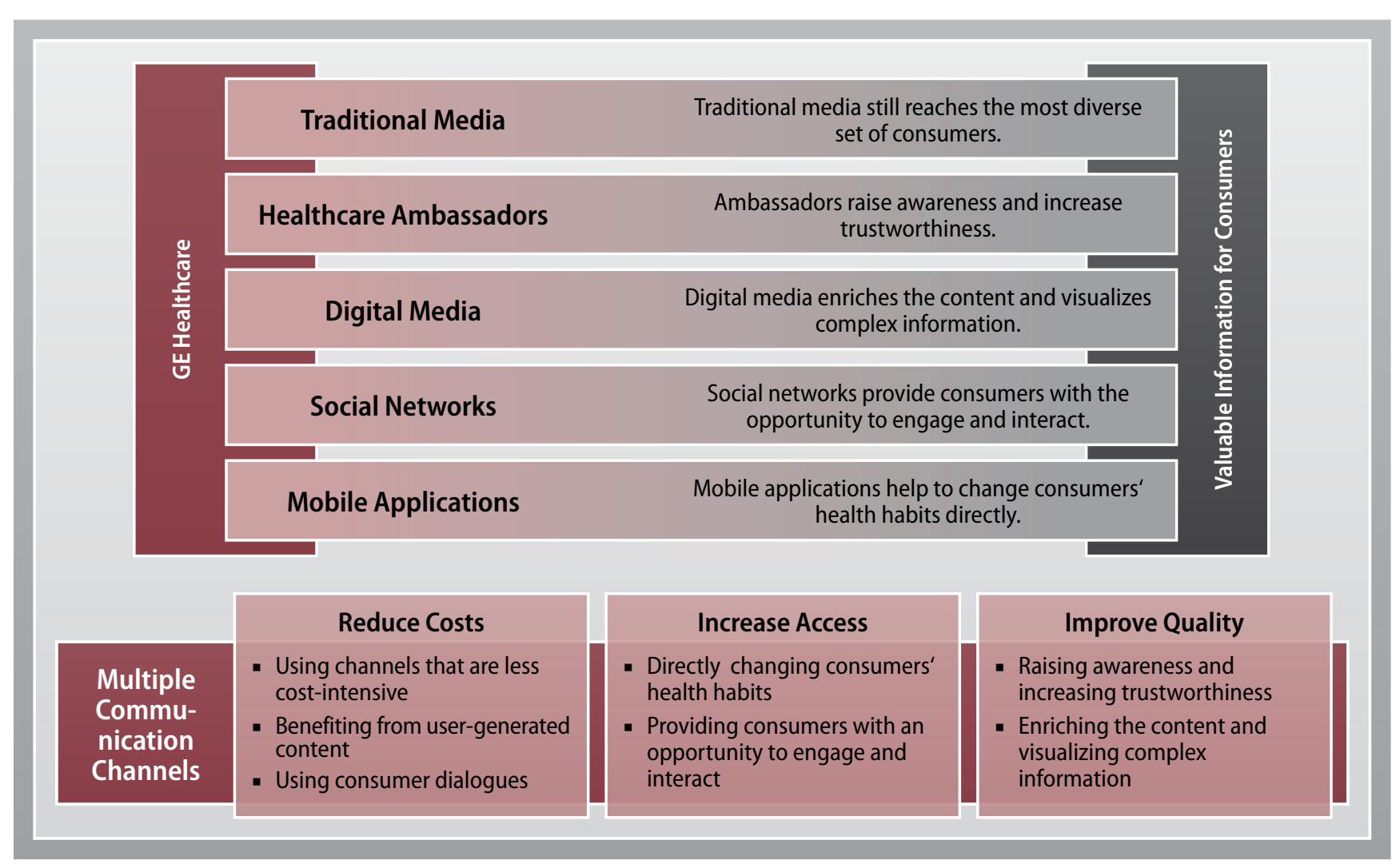


more affordable health technologies and services. GE is using the power of reverse innovation - a new model of product development that empowers local teams to develop technologies in their country, for their country - to address local needs and enable access to technology where it may never have been available before. Examples include the US\$ $500 \mathrm{MACi}$ cardiology device for India, which allows physicians to give scans for the cost of a bottle of water, as well as the Brivo CT for China, which brings lower-cost CT technology to hospitals that were not able to afford it before.

GE also helps employees to manage their health more efficiently. Today, more than 100 GE sites have achieved HealthAhead certification, with more than 300 additional sites planned in 2011. Nearly 100,000 employees participated in this year's HealthAhead Day, a global program designed to encourage employees to make healthy choices.

An analysis of GE's brand image with healthcare professionals before and after the start of the initiative showed a significant impact. GE is increasingly perceived as a reliable and innovative high-tech company; over $89 \%$ of clinicians felt more positive after being exposed to healthymagination and $82 \%$ indicated that it made them at least somewhat more likely to purchase GE products in the future.

Finally, due to an improved business performance and a reduction in expenditures on healthcare for its employees and retirees, GE now rewards its investors with a long-term organic growth in the healthcare sector, which amounts to 2-3 times the U.S. Gross Domestic Product.

\section{Future Challenges}

However, there is still room for improvement. To date, three main obstacles have been identified. First, GE realized that making an impact on health is extremely complex. Thus, collaboration is essential in terms of identifying the best ideas and driving innovation that will result in meaningful change. To solve this challenge, recent healthymagination activities have been extended to partnerships with local governments. For example, in Saudi Arabia GE is cooperating with the Ministry of Health to make a significant impact on the country's healthcare delivery system with a specific emphasis on cardiac and women's health.

Although healthymagination is a global strategy and healthcare segments around the world are struggling with cost, quality and access, each of these segments has very specific needs and demands. It is a challenging task to adapt the global healthymagination initiative to local conditions and to promote it in regions and countries where GE has so far not been a dominant player. The pursued strategy of setting up country teams, enabling them to create innovations in the country, for the country and making them more responsive to local demands can only be successful if GE is able to support these local initiatives with the R\&D backbone of the global company. As a first step in this process, GE moved its global X-ray leadership team, including extensive research and development facilities, to China in order to be closer to developing markets.

Surprisingly, another challenge for healthymagination is internal rather than external. The message and the values of the campaign have been well received by clinicians, but GE's sales team still has to be motivated to use healthymagination as an additional tool to engage with customers. Although $90 \%$ of GE sales representatives believe that the healthymagination message had a positive impact on customers' perception, its commercial activation needs to be stepped up. Sales representatives need to be trained better to overcome customer misconceptions that reduced costs are equivalent to reduced prices and improved quality is exclusively linked to increased reliability. Also, the third pillar of the initiative, increased access, will need to be emphasized more, since only half of the sales teams surveyed could name all three pillars of the initiative.

There is a strong correlation between cost and access, especially in developing countries. If GE is able to significantly reduce costs of health procedures, this will directly lead to a broader access and adoption of these procedures in the emerging world. To achieve this, GE opened its innovation approach and included external partners with a fresh view on healthcare problems. The healthymagination challenge is a crowdsourcing-based open innovation approach by GE and several venture capital partners. It is an open call for businesses, entrepreneurs, innovators and students with breakthrough ideas for the detection and treatment of breast cancer. Up to US\$ 100 million may be invested globally and will enable GE to gather innovative ideas and discover new potential partners.

\section{Conclusion}

GE's strength is to discover substantial global trends and customer needs, develop a strategic focus and not only translate this strategy into a companywide initiative but also actively engage external stakeholders. Fixing the problems of healthcare is a huge challenge that certainly cannot be tackled by a company on its own. However, GE's healthymagination initiative shows how a new understanding of innovation, a broader stakeholder orientation and new communication channels can contribute to meeting the healthcare challenge.

Healthcare providers should replace their emphasis on costintensive, performance-driven innovations with more affordable, simpler solutions that target specific needs. Promising fields for such innovations are, for example, information acceleration, efficient technology, local access and engaging patients. Companies should consider reversing the usual innovation funnel, through which high-tech, high-cost innovations are transferred from the developed world into the emerging markets, to an approach where resource-optimized solutions are penetrated the other way round.

With the shift to a multiple stakeholder orientation, companies can better understand and discover market needs as they gain a broader perspective. Such companies are able to determine the challenges all healthcare market players are faced with and thus can create products and services that will suit their needs. In order 
to do so they have to open up on multiple levels, including innovation and communication.

The use of new and multiple forms of communication creates easy access to clear, actionable information. Thus, healthcare providers can help consumers participate in improving the quality and cost of the care they receive.

\section{References}

Chesbrough, H.W. (2003): Open Innovation: The New Imperative for Creating and Profiting from Technology, Boston.

Ferrell, O.C./Gonzalez-Padron, T.L./Hult, G.T.M./Maignan, I. (2010): From Market Orientation to Stakeholder Orientation, in: Journal of Public Policy \& Marketing, 29, 1, pp. 93-96.

GE/Cleveland Clinic/Ochsner Health System (2010): Better Health Study, http://www.healthymagination.com/projects/better-health-study, accessed 13.05.2011.

HowCast (2011): GE Healthymagination Case Study, http://www.howcast.com/ videos/407601-HowcastGE-Healthymagination-Case-Study, accessed 16.05.11.

Kotler, P./Kartajaya, H./Setiawan, I. (2010): Marketing 3.0 - From Products to Customers to the Human Spirit, Hoboken.

Li, C./Bernoff, J. (2008): Groundswell - Winning in a World Transformed by Social Technologies, Boston.

Marketing Science Institute (2010): MSI Research Priorities 2010-2012 - A Guide to MSI Research Programs and Procedures, http://www.msi.org/ research, accessed 15.05.2011.

OECD (2010): OECD Health Data 2010 - Statistics and Indicators, http://stats. oecd.org, accessed 16.05.2011.
Porter, M.E./Kramer, M.R. (2011): Creating Shared Value, in: Harvard Business Review, 89, 1/2, pp. 62-77.

Rust, R.T./Moorman, C./Bhalla, G. (2010): Rethinking Marketing, in: Harvard Business Review, 88, 1/2, pp. 94-101.

Trumann, M./Herhausen, D. (2008): Ecomagination - Ein Unternehmen positioniert sich nachhaltig, in: Marketing Review St. Gallen, 25, 4, pp. 23-27.

Ulwick, A.W. (2005): What Customers Want: Using Outcome-Driven Innovation to Create Breakthrough Products and Services, Boston.

\section{The Authors}

Dr. Dennis Herhausen

Project Leader at the Institute of Marketing, University of St. Gallen

E-Mail: dennis.herhausen@unisg.ch

Dipl.-Ök. Markus Trumann

Pricing Leader, GE Healthcare Germany

E-Mail: markus.trumann@ge.com

Prof. Dr. Marcus Schögel

Director at the Institute of Marketing, University of St. Gallen

E-Mail: marcus.schoegel@unisg.ch

\section{Schärft Ihren Marketingblick.}

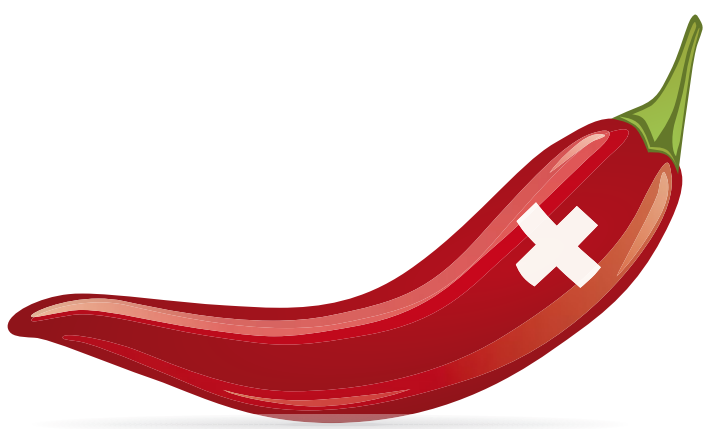

\section{Lesen Sie sich in Führung}

Wer im Marketing an der Spitze liegen will, liest sich mit Marketing Review St. Gallen in Führung. Hierin erfahren Sie alles über innovative Marketingansätze und zukunftsweisende Marketingkonzepte. Zudem profitieren Sie vom Wissen der Vordenker aus Wissenschaft und Praxis.

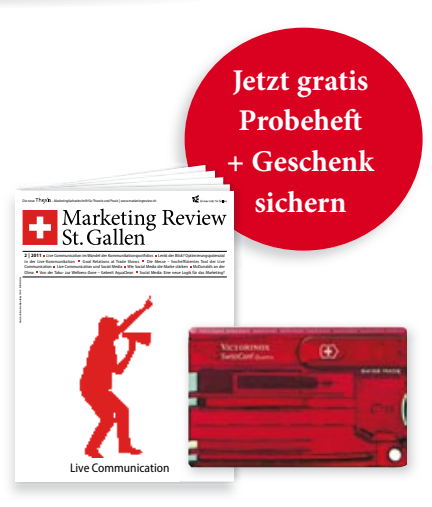

Ja, ich möchte Marketing Review St. Gallen kennenlernen. Als Geschenk erhalte ich die Victorinox SwissCard Quattro.

Bitte senden Sie mir die nächste Ausgabe sowie mein Geschenk kostenfrei zu. Wenn mir Marketing Review St. Gallen gefalltt, brauche ich nichts weiter zu tun. Ich erhalte dann 6 Ausgaben zum Jahresvorzugspreis von $€ 155$,- (inkl. Versand und MwSt.). Der Bezug ist vollflexibel und kann jederzeit zur nächsten erreichbare Ausgabe beendet werden. Ich gehe also keinerlei Risiko ein. Möchte ich Marketing Review St. Gallen nich weiterlesen, melde ich mich innerhalb von 14 Tagen nach Erhalt des Heftes schriftlich. Ein Angebot der Springer Fachmedien Wiesbaden GmbH, GF: Dr. R. Birkelbach, AG Wiesbaden HRB 9754. Einfach Coupon
ausfullen und faxen an: $+49(0) 611-7878412$. Oder bestellen Sie einfach per Tel.: +49 (0) $6221-3454303$ ausfüllen und faxen an: $+49(0) 611-7878412$. Oder bestellen Sie einfach
oder E-Mail: gabler-service@springer.com oder unter www.readtolead.de

$\overline{\text { FIRMA }}$

ABTEILUNG

VORNAME / NAME

BRANCHE

STRASSE / NR.

PLZ / ORT

\section{TELEFON}

E-MAIL-ADRESSE

\section{DATUM / UNTERSCHRIFT}

1162

C0001905

Ihre Adresse wird nicht an Dritte zu Werbezwecken weitergegeben.

Die Verwendung Ihrer Daten dient ausschließlich für Produktinformationen durch den Verlag. Sie können jederzeit per E-Mail (widerspruch@springer.com) widersprechen. 